\title{
Trends in missed presentations and late HIV diagnosis in a UK teaching hospital: a retrospective comparative cohort study
}

\author{
Jared Wohlgemut ${ }^{* \dagger}$, Timothy Lawes ${ }^{2+}$ and Robert BS Laing ${ }^{2 \dagger}$
}

\begin{abstract}
Background: Late diagnosis is an important cause of HIV-related morbidity, mortality and healthcare costs in the UK and undiagnosed infection limits efforts to reduce transmission. National guidelines provide recommendations to increase HIV testing in all healthcare settings. We evaluated progress towards these recommendations by comparing missed opportunities for HIV testing and late diagnosis in two six year cohorts from North East Scotland.

Methods: We reviewed diagnostic pathways of all patients newly diagnosed with HIV referred to infectious diseases and genito-urinary medicine services between 1995 and $2000(n=48)$ and 2004 to 2009 ( $n=117)$. Missed presentations (failure to diagnose $\leq 1$ month of a clinical or non-clinical indicator for testing), late diagnosis (CD4 < $350 \mathrm{cell} s / \mathrm{mm}^{3}$ ), and time to diagnosis (months from first presentation to diagnosis) were compared between cohorts using $\chi^{2}$ and log-rank tests. Determinants of missed presentation were explored by multivariate logistic regression. Breslow-Day tests assessed change in diagnostic performance by patient subgroup.

Results: There were significant decreases in missed presentations (33\% to $17 \% ; P=0.02$ ) and time to diagnosis (mean 17 months to 4 months; $P=0.005$ ) but not in late diagnosis (56\% vs. 60\%; $P=0.57$ ) between earlier and later cohorts. In the later cohort patients were significantly more likely to have acquired HIV abroad and presented with early HIV disease, and testing was more likely to be indicated by transmission risk or contact with GUM services than by clinical presentation. Missed presentation remained significantly less likely in the later cohort $(\mathrm{OR}=$ $0.28,95 \% \mathrm{Cl} 0.11$ to $0.72 ; P=0.008$ ) after adjustment for age, transmission risks and number of clinical indicators. Reductions in missed presentation were greater in patients $<40$ years, of non-UK origin, living in least deprived neighbourhoods and with early disease at presentation $(P<0.05)$. 27\% of missed presentations occurred in primary care and $46 \%$ in general secondary care.

Conclusions: While early diagnosis has improved in epidemiological risk groups, clinical indications for HIV testing continue to be missed, particularly in patients who are older, of UK origin and from more deprived communities. Increasing testing in non-specialist services is a priority.
\end{abstract}

Keywords: HIV, Cohort studies, Delayed diagnosis, Adult

\section{Background}

Diagnosis is a critical limiting factor in the treatment and control of HIV/AIDS worldwide. Globally, up to 90\% of people living with HIV may be unaware of their status [1]: with estimates ranging from $21 \%$ to $30 \%$ in

\footnotetext{
*Correspondence: j.wohlgemut.09@aberdeen.ac.uk

† Contributed equally

${ }^{1}$ School of Medicine and Dentistry, University of Aberdeen, Aberdeen, UK Full list of author information is available at the end of the article
}

developed nations [2,3]. In the context of a maturing pandemic, there has been a shift in attitudes towards testing, from an emphasis on protection of civil rights to improving public health, matched by models of provider, rather than patient, initiated testing [4]. Effectiveness of strategies for increasing testing and diagnosis is dependent upon regional epidemic status [1], but responses have been varied even within areas of low-HIV prevalence. Many countries, including the USA and Canada

\section{(Ciomed Central}


have recommended universal 'opt-out' testing in all general healthcare settings.

In the UK $25 \%$ of HIV infections are undiagnosed, undermining efforts to reduce transmission [5], and late diagnosis is an important cause of HIV-related morbidity [6], mortality [7] and healthcare costs [8]. A national audit of deaths among HIV infected adults found that late diagnosis was the leading remediable cause of HIVrelated death [7]. The responsibilities of all health workers and services in reducing the diagnosis gap has been emphasised by leaders across disciplines [9]. In 2008 National guidelines for HIV testing were updated with the aim of increasing HIV testing in all healthcare settings [10]. Despite evidence of cost-effectiveness in low prevalence areas [11], routine 'opt-out' testing was not recommended, except in areas with adult prevalence > $0.2 \%$. Instead, testing is to be offered universally in selected services, to those with epidemiologic risk-factors and to children or adults presenting with one or more prescribed clinical indicator diseases.

Beyond national surveillance [12], there is a need to describe progress towards national standards for testing and patterns in under-diagnosis at a regional level. Demographic changes in the local HIV population affected trends in missed acute HIV presentations in a study from Liverpool [13]. Increased testing has been associated with reductions in undiagnosed HIV infections in gay men in Scotland [14], but trends in diagnosis outside of high-risk groups are largely unknown.

This study compared the diagnostic pathways of HIV positive patients in North East Scotland diagnosed within two cohorts over a 15 year period, with the aim of describing trends in missed HIV presentations, late diagnosis and time-delay to diagnosis and associated risk-factors.

\section{Methods}

\section{Study design and setting}

Aberdeen Royal Infirmary (ARI) is a tertiary referral centre and acute teaching hospital, serving a population of 500,000 in the North East of Scotland (NHS Grampian). Outpatient HIV care is jointly provided by genitourinary medicine (GUM) and infectious disease (ID) departments, with inpatient care in ARIs regional infectious diseases unit. Shared provision started in 1999, prior to which all patients were cared for by infectious disease specialists although HIV testing, including anonymous testing, took place in GUM throughout both time periods.

This comparative retrospective cohort study contrasted the diagnostic pathways of patients newly diagnosed with HIV and referred to GUM or ID departments at ARI between 1995 and $2000(\mathrm{n}=48)$ with those diagnosed between 2004 and $2009(\mathrm{n}=117)$.

\section{Definitions}

Recommendations from the BHIVA guidelines (2008) were used to define clinical (presentations and haematological abnormalities) and non-clinical (service and epidemiological risk-groups) indicators for testing. First case-note or laboratory system record of any indicator was taken to be the first presentation. Declarations of past transmission risks or serological evidence of past infection, without prior documentation, were considered as presentations at time of recording.

The primary outcome was 'missed presentation', defined as failure to diagnose HIV within one month of a clinical or non-clinical indicator for testing. Secondary outcomes included, 'late' diagnosis (CD4 count < 350/ $\mathrm{mm}^{3}$ at diagnosis), 'very late' diagnosis (CD4 count < $200 / \mathrm{mm}^{3}$ at diagnosis) and time to diagnosis (months from first presentation to diagnosis).

HIV clinical staging, and clinical diagnosis of AIDS, at first presentation and diagnosis were defined by World Health Organisation (WHO) criteria [15]. Patient postcode was linked to neighbourhood (small-area) Scottish Index of Multiple Deprivation (SIMD) decile and quintile [16] to provide a proxy for socio-economic status $[17,18]$.

\section{Study population and data collection}

All patients $>18$ years of age, newly diagnosed with HIV and referred to infectious disease and GUM services in ARI within the two time periods were identified by anonymised-linked clinic records, patient management systems and notes of current or deceased patients. Patients moving outside of region were excluded as detailed clinical records were not available. Routinely collected data in case-notes from secondary care and electronic laboratory records were reviewed for each patient from earliest documented clinical or non-clinical indication for HIV testing (first presentation) to actual diagnosis. All presentations were documented up to point of diagnosis. Presentations to primary care were considered only where accompanied by documentation in electronic summaries from the patient's general practitioner (GP). Such summaries are typically provided on referral to, or on request from, secondary care in the region.

Research carried out was in compliance with section 25 of the Helsinki Declaration [19]. Permission to access medical notes was granted by the Clinical Effectiveness Facilitator from Aberdeen Royal Infirmary's Medical Records Department (Project ID: 2035).

\section{Data analysis}

Frequency of missed presentation, late and very late diagnosis and time-delay to diagnosis were compared between the six-year cohorts using Fisher's exact and 
Log-rank tests. Cohort characteristics and indicators for testing at first presentation were compared using Fisher's exact or Mann-Whitney U tests. Risk factors for missed presentation were explored via univariate and multivariate logistic regression. Cohort (time period) was included as an a priori determinant and other covariates were entered into a multivariate model if $P<$ 0.10 in univariate analysis. Breslow-Day tests were used to investigate heterogeneity in rates of missed presentation in later versus earlier cohorts across patient subgroups. Further comparison of time to diagnosis between cohorts was made using Kaplan-Meier curves and multivariate Cox-regression adjusting for case-mix.

Finally, in patients with a missed presentation we assessed disease progression by time of diagnosis by comparing the number of clinical indicators for testing, clinical stage and presence or absence of AIDS defining illness at first presentation and diagnosis using relatedsamples Wilcoxon-signed rank tests. Likelihood of immunologically advanced disease (CD $4<200$ cells/ $\mathrm{mm}^{3}$ ) at diagnosis was compared between patients with and without missed presentation by logistic regression adjusting for baseline characteristics.

\section{Results}

\section{Cohort characteristics}

Compared with the earlier cohort, patients diagnosed between 2004 and 2009 were significantly more likely to have acquired HIV from outside the UK (59\% vs. 37\%; $P$ $=0.01$ ), be from less-deprived neighbourhoods and present with seroconversion illness or early HIV disease, despite comparable CD4 counts at diagnosis (Table 1).

\section{Primary outcomes}

Overall, $22 \%$ of diagnoses were preceded by at least one missed presentation $(n=36)$. Frequency of late and very late diagnosis were $57 \%$ and $40 \%$ respectively and mean time to diagnosis was 8 months (95\% CI: 4 to 12 months). There were significant decreases in missed presentations ( $33 \%$ to $17 \% ; P=0.02$ ) and time to diagnosis (mean 17 months to 4 months; $P=0.005$ ) between earlier and later cohorts, but not in frequencies of late (56\% vs. $61 \% ; P=0.57)$ or very late $(39 \%$ vs. $44 \% ; P=$ $0.53)$ diagnosis.

\section{Indicators for testing at first presentation}

Patients in the later cohort were less likely to present with a clinical indicator disease (63\% vs. $88 \% ; P=0.005)$ and more likely to present with epidemiological risk factors or via a service applying universal testing (Table 2). The higher proportion of patients acquiring HIV in high-risk regions (HIV prevalence $>1 \%$ ) and increased contact with GUM services largely explained these trends. Significantly fewer first presentations with candidiasis $(19 \%$ to $8 \%$; $P=0.04)$ and bacterial pneumonia $(8 \%$ to $2 \% ; P=0.04$ ) were observed in the later cohort, otherwise clinical presentations were broadly comparable between the two cohorts $(P>0.10$ for all $)$ (Figure 1).

\section{Missed presentations}

Stratifying by clinical indicator disease (Figure 1), no presentations with AIDS defining illness were missed in either time period, whilst 8 of 9 blood dyscrasias were missed. $\chi^{2}$ tests revealed a lower risk of missed presentation with sexually transmitted infection (STI) in the later cohort $(13 \%$ vs. $50 \%$; $\mathrm{P}=0.02)$ and a nonsignificant decline in missed seroconversion illness $(0 \%$ vs. $33 \% ; \mathrm{P}=0.17$ ). Presentations with pneumonia and hepatitis $\mathrm{B}$ or $\mathrm{C}$ were persistently missed. In patients not diagnosed at first presentation 13 (36\%) had at least one further documented missed presentation before diagnosis. The majority of missed presentations occurred in non-specialist hospital services $(47 \%)$ or primary care $(27 \%)$, with $13 \%$ in GUM and $7 \%$ in antenatal services.

\section{Determinants of missed presentation}

In univariate logistic regressions lower risks of missed presentations were predicted by age $<40 \mathrm{yrs}$, origin in high-risk regions, MSM, partner HIV positive, diagnosis in the later cohort and higher number of indicators for testing (Table 3). In a final multivariate model missed presentation remained significantly less likely in the later cohort $(\mathrm{OR}=0.28,95 \% \mathrm{CI} 0.11$ to $0.72 ; P=0.008)$ after adjustment for these covariates. IV drug use was associated with a large, but non-significant increased risk of missed presentation.

Stratifying by patient sub-group revealed a significantly greater reduction in risk of missed presentation in the later cohort amongst younger patients $(<40 \mathrm{yrs})$, living in least-deprived neighbourhoods and presenting with early or asymptomatic disease (Breslow-day tests; $P$ $<0.05$ ) (Figure 2). Improved diagnosis was also noted in those with a CD4 count > 200 at diagnosis, or from high-risk areas, although differences within strata were non-significant.

\section{Time to diagnosis}

Kaplan-Meier curves reflected a higher proportion of diagnoses made at first presentation in the later cohort as well as reduced time to diagnosis in those missed at first presentation (median delay 10 vs. 34 months; $p=$ 0.005) (Figure 3). A multivariate Cox-regression model revealed a non-significant improvement in rate of (time to) diagnosis (adjusted $\mathrm{HR}=1.36,95 \% \mathrm{CI}$ : 0.96 to 1.94 ; $P=0.084$ ) after adjusting for case-mix: the proportion of patients diagnosed within one year of first 
Table 1 Demographic and clinical characteristics by cohort

\begin{tabular}{|c|c|c|c|c|}
\hline & $\begin{array}{c}\text { All } \\
\mathrm{n}=165\end{array}$ & $\begin{array}{c}1995-2000 \\
n=48\end{array}$ & $\begin{array}{c}2004-2009 \\
n=117\end{array}$ & $P$ value \\
\hline Gender (female) & 47 (29\%) & $10(21 \%)$ & $37(32 \%)$ & 0.163 \\
\hline Age, years & $38(10)$ & $38(9)$ & $38(11)$ & 0.810 \\
\hline $\mathrm{SIMD}^{\dagger}$, quntile & & & & 0.040 \\
\hline 1 (most deprived) & $24(15 \%)$ & $10(21 \%)$ & $14(13 \%)$ & \\
\hline 2 & $22(14 \%)$ & $8(17 \%)$ & $13(13 \%)$ & \\
\hline 3 & $38(24 \%)$ & $13(27 \%)$ & $25(22 \%)$ & \\
\hline 4 & $38(24 \%)$ & $9(19 \%)$ & $29(26 \%)$ & \\
\hline 5 (least deprived) & $38(24 \%)$ & $8(17 \%)$ & $30(27 \%)$ & \\
\hline Origin & & & & 0.226 \\
\hline UK & $108(66 \%)$ & $36(75 \%)$ & $72(62 \%)$ & \\
\hline sub-Saharan Africa & $39(24 \%)$ & $9(19 \%)$ & $30(26 \%)$ & \\
\hline Other & $18(11 \%)$ & $3(6 \%)$ & $15(13 \%)$ & \\
\hline Area of presumed acquisition & & & & 0.026 \\
\hline UK & $78(47 \%)$ & $30(63 \%)$ & $48(41 \%)$ & \\
\hline Europe & $10(6 \%)$ & $2(4 \%)$ & $8(7 \%)$ & \\
\hline sub-Saharan Africa & $58(35 \%)$ & $14(29 \%)$ & $44(38 \%)$ & \\
\hline Asia/SE Asia & $19(12 \%)$ & $2(4 \%)$ & $17(15 \%)$ & \\
\hline UK origin acquired in high-risk area. & $26(16 \%)$ & $6(12 \%)$ & $20(17 \%)$ & \\
\hline Previous (negative) HIV test & $51(31 \%)$ & $13(27 \%)$ & $38(33 \%)$ & 0.469 \\
\hline Months since last HIV test (if occurred) & $41(42)$ & $29(20)$ & $45(47)$ & 0.090 \\
\hline Clinical staging at first presentation (WHO) & & & & 0.010 \\
\hline Primary HIV infection & $3(2 \%)$ & $0(0 \%)$ & $3(3 \%)$ & \\
\hline Stage 1 & $102(62 \%)$ & $23(48 \%)$ & $79(68 \%)$ & \\
\hline Stage 2 & $11(7 \%)$ & $5(10 \%)$ & $6(5 \%)$ & \\
\hline Stage 3 & $24(15 \%)$ & $9(18 \%)$ & $15(13 \%)$ & \\
\hline Stage 4 & $25(15 \%)$ & $11(23 \%)$ & $14(12 \%)$ & \\
\hline Clinical staging at diagnosis ( $\mathrm{WHO})$ & & & & 0.002 \\
\hline Primary infection & $2(1 \%)$ & $0(0 \%)$ & $2(2 \%)$ & \\
\hline Stage 1 & $84(51 \%)$ & $14(30 \%)$ & $70(60 \%)$ & \\
\hline Stage 2 & $12(7 \%)$ & $6(13 \%)$ & $6(5 \%)$ & \\
\hline Stage 3 & $29(18 \%)$ & $14(29 \%)$ & $15(13 \%)$ & \\
\hline Stage 4 & $38(23 \%)$ & $14(29 \%)$ & $24(21 \%)$ & \\
\hline $\mathrm{Cd} 4$ count at diagnosis (cells/mm³) & & & & 0.517 \\
\hline$<200$ & $66(40 \%)$ & $21(44 \%)$ & $45(39 \%)$ & \\
\hline $200-350$ & $28(17 \%)$ & $8(17 \%)$ & $20(17 \%)$ & \\
\hline$>350$ & 71 (43\%) & 19 (40\%) & 52 (44\%) & \\
\hline
\end{tabular}

${ }^{*} \chi^{2}$ test of difference in proportion missed, $P=0.02$. Otherwise non-significant. ${ }^{\dagger}$ Scottish Index of Multiple Deprivation.

presentation was $77 \%$ in the earlier cohort and $92 \%$ in the later cohort.

\section{Associations between missed presentation and disease progression}

In those patients with a missed presentation $(\mathrm{n}=36)$, the median number of clinical indicator diseases increased significantly from 1 at first presentation to 3 at diagnosis (Related-samples Wilcoxon-Signed rank tests, $P<0.001)$. Progression to AIDS (25\%) or higher WHO clinical staging (53\%) was common between missed presentation and diagnosis. Compared with those diagnosed at first presentation, patients with $\geq 1$ missed presentation were also substantially more likely to have immunologically advanced disease (CD4 < 200 cells $\left./ \mathrm{mm}^{3}\right)$ at diagnosis: $74 \%$ vs. $30 \%(\mathrm{OR}=6.9,95 \% \mathrm{CI}$ : 3.0 to $16.2 ; P<0.001)$.

\section{Discussion}

This study looked for evidence of improvements in early HIV diagnosis in response to national strategies to increase testing in all healthcare settings. Diagnostic pathways were compared in two cohorts of newly diagnosed HIV patients from a 15 year period in North East 
Table 2 Summary of indicators for HIV Testing at first presentation

\begin{tabular}{|c|c|c|c|c|}
\hline & $\begin{array}{c}\text { All } \\
\mathrm{n}=165\end{array}$ & $\begin{array}{c}1995-2000 \\
n=48\end{array}$ & $\begin{array}{c}2004-2009 \\
n=117\end{array}$ & $P$ value \\
\hline \multicolumn{5}{|l|}{ Summary } \\
\hline Median no. clinical indicators & $1(0-2)$ & $1(1-2)$ & $1(0-1)$ & 0.002 \\
\hline Median number of all non-clinical indicators & $2(1-2)$ & $1(1-2)$ & $2(1-3)$ & $<0.001$ \\
\hline Median number of all clinical \& non-clinical indicators & $3(2-4)$ & $3(2-4)$ & $3(2-4)$ & 0.697 \\
\hline Services indicator (any) & $102(62 \%)$ & $19(40 \%)$ & $83(71 \%)$ & $<0.001$ \\
\hline Ante-natal/ToP & $14(9 \%)$ & $4(8 \%)$ & $10(9 \%)$ & 0.964 \\
\hline GUM & $61(37 \%)$ & $8(17 \%)$ & $53(45 \%)$ & 0.001 \\
\hline TB, Hep B/C, lymphoma & $27(16 \%)$ & $8(17 \%)$ & $19(16 \%)$ & 0.964 \\
\hline Occupational health or screening* & $11(7 \%)$ & $3(6 \%)$ & $8(7 \%)$ & 0.891 \\
\hline Transmission risk indicator (any) & $132(80 \%)$ & $33(69 \%)$ & $99(85 \%)$ & 0.021 \\
\hline Country of origin high prevalence (> 1\%) & $53(32 \%)$ & $10(21 \%)$ & $43(37 \%)$ & 0.047 \\
\hline Men with disclosed sexual contact with men (MSM) & $46(28 \%)$ & $14(29 \%)$ & $32(27 \%)$ & 0.813 \\
\hline IVDU & $8(5 \%)$ & $2(4 \%)$ & $6(5 \%)$ & 0.794 \\
\hline Sexual contact abroad & $42(26 \%)$ & $10(21 \%)$ & $32(28 \%)$ & 0.383 \\
\hline Partner HIV+ & $24(15 \%)$ & $6(13 \%)$ & $18(15 \%)$ & 0.633 \\
\hline Blood donors, dialysis patients or organ donors/recipients & $6(4 \%)$ & $4(8 \%)$ & $2(2 \%)$ & 0.039 \\
\hline Non-clinical indicator (any transmission risk or service indicator) & $147(89 \%)$ & $37(77 \%)$ & $110(94 \%)$ & 0.002 \\
\hline Clinical Indicator diseases (any) & $119(72 \%)$ & $42(88 \%)$ & $74(63 \%)$ & 0.005 \\
\hline
\end{tabular}

Indicators as recommended by national guidelines for HIV testing, except *.

Scotland. We demonstrated a significant decrease in missed presentations and time to diagnosis between the two time periods. However, patient groups, clinical presentations, and services in which opportunities for early diagnosis continue to be missed were also identified. Delay to diagnosis and missed presentation were strongly associated with disease progression at time of diagnosis.

As reported elsewhere in the UK [13], changes in socio-demographics of the HIV population had important impacts upon first presentations. We noted increases in patients from, or acquiring HIV in, regions of high HIV prevalence, and living in less deprived neighbourhoods. In North East Scotland these trends are related since contact with hyperendemic regions is largely related to a mobile labour-force in the oil industry [20]. An important minority diagnosed in occupational health screening emphasises the importance of HIV care for workers in globalised industries [21]. Patient ethnicity is an important epidemiological risk factor that should be recorded at first contact with all UK healthcare services [10]. Substantial reductions in missed presentations in those acquiring HIV in highrisk regions, suggested increased awareness of transmission risks, while patient factors, including access to alternative health insurance, may explain discordance with findings of barriers to diagnosis for some migrant populations [22].

Our findings also warn against stereotyping the 'at risk' patient [23]: $20 \%$ of diagnoses occurred in those without transmission risks. Missed presentations persisted in patients who were older, of UK origin and from more deprived communities. Delayed HIV diagnosis in older patients is common [13,23] and of national importance. Across the UK the proportion of new diagnoses made in those $>40$ years increased from $23 \%$ to $38 \%$ between 1995 and 2009[24] and older age predicts poorer outcomes from anti-retroviral therapy, particularly for immunologically advanced disease [25]. Overemphasis on ethnicity, without reference to contextual factors such as deprivation and social networks, impair effective prevention of other infectious diseases including sexually STIs [26] and tuberculosis [27]. Regional patterns in transmission risks may be of more importance to clinicians than national epidemiology. A high proportion of heterosexual and IVDU transmission amongst those of UK origin has been noted in the North East of Scotland [20]. Under-diagnosis in IVDUs may be particularly important given associations with high-risk sexual behaviours [28] and TB transmission [29].

In common with a study of acute HIV presentations from Liverpool [13], we found consistent patterns of all presentations in both cohorts. Despite this we found limited evidence that strategies to increase HIV diagnosis have improved our ability to recognise early clinical indicators in the absence of epidemiological risk-factors. In particular, unexplained haematological abnormalities, bacterial pneumonias and viral hepatitis frequently failed to prompt HIV testing. This may 


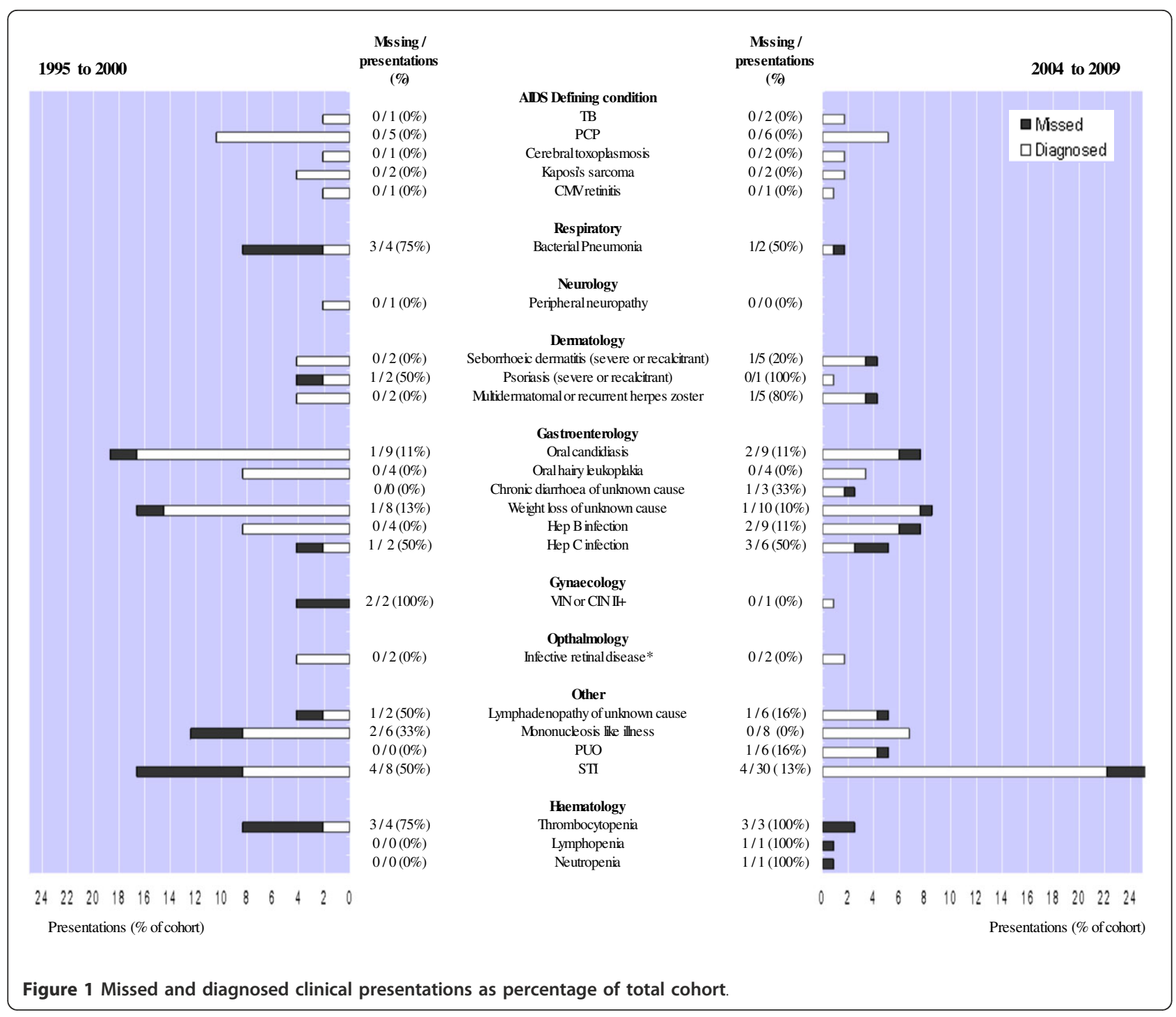

Table 3 Risk-factors for missed presentation by univariate and multivariate logistic regression

\begin{tabular}{|c|c|c|c|c|}
\hline & \multicolumn{2}{|c|}{ Univariate Regression } & \multicolumn{2}{|c|}{ Multivariate Regression } \\
\hline & OR $(95 \% \mathrm{Cl})$ & $P$ value & OR $(95 \% \mathrm{Cl})$ & $P$ value \\
\hline Time period (later) & 0.41 (0.19 to 0.89 ) & 0.024 & 0.28 (0.11 to 0.72$)$ & 0.008 \\
\hline Age, per 10 years & 1.79 (1.20 to 2.55$)$ & 0.004 & 1.69 (1.09 to 2.64$)$ & 0.007 \\
\hline \multicolumn{5}{|l|}{ Transmission risk: } \\
\hline Country of origin high prevalence & 0.35 (0.14 to 0.90$)$ & 0.029 & $0.39(0.12$ to 1.21$)$ & 0.103 \\
\hline MSM & 0.45 (0.17 to 1.15$)$ & 0.097 & 0.30 (0.10 to 0.88$)$ & 0.028 \\
\hline IVDU & 3.91 (0.92 to 16.5$)$ & 0.064 & 4.32 (0.82 to 23.0$)$ & 0.086 \\
\hline Partner HIV+ & 0.13 (0.02 to 1.01$)$ & 0.051 & 0.09 (0.01 to 0.81$)$ & 0.032 \\
\hline Any Service indicator & 0.54 (0.25 to 1.03$)$ & 0.100 & $-^{\dagger}$ & \\
\hline Number of clinical indicators & 0.86 (0.62 to 1.20$)$ & 0.376 & 0.60 (0.37 to 0.97$)$ & 0.032 \\
\hline Number of non-clinical indicators & 0.49 (0.32 to 0.75$)$ & 0.001 & $-*$ & \\
\hline Number of all indicators & 0.63 (0.46 to 0.87 ) & 0.006 & $-^{*}$ & \\
\hline
\end{tabular}

\footnotetext{
* Excluded as co-linearity with individual non-clinical or clinical indicators ${ }^{\dagger}$ Inclusion did not improve model fit.
} 


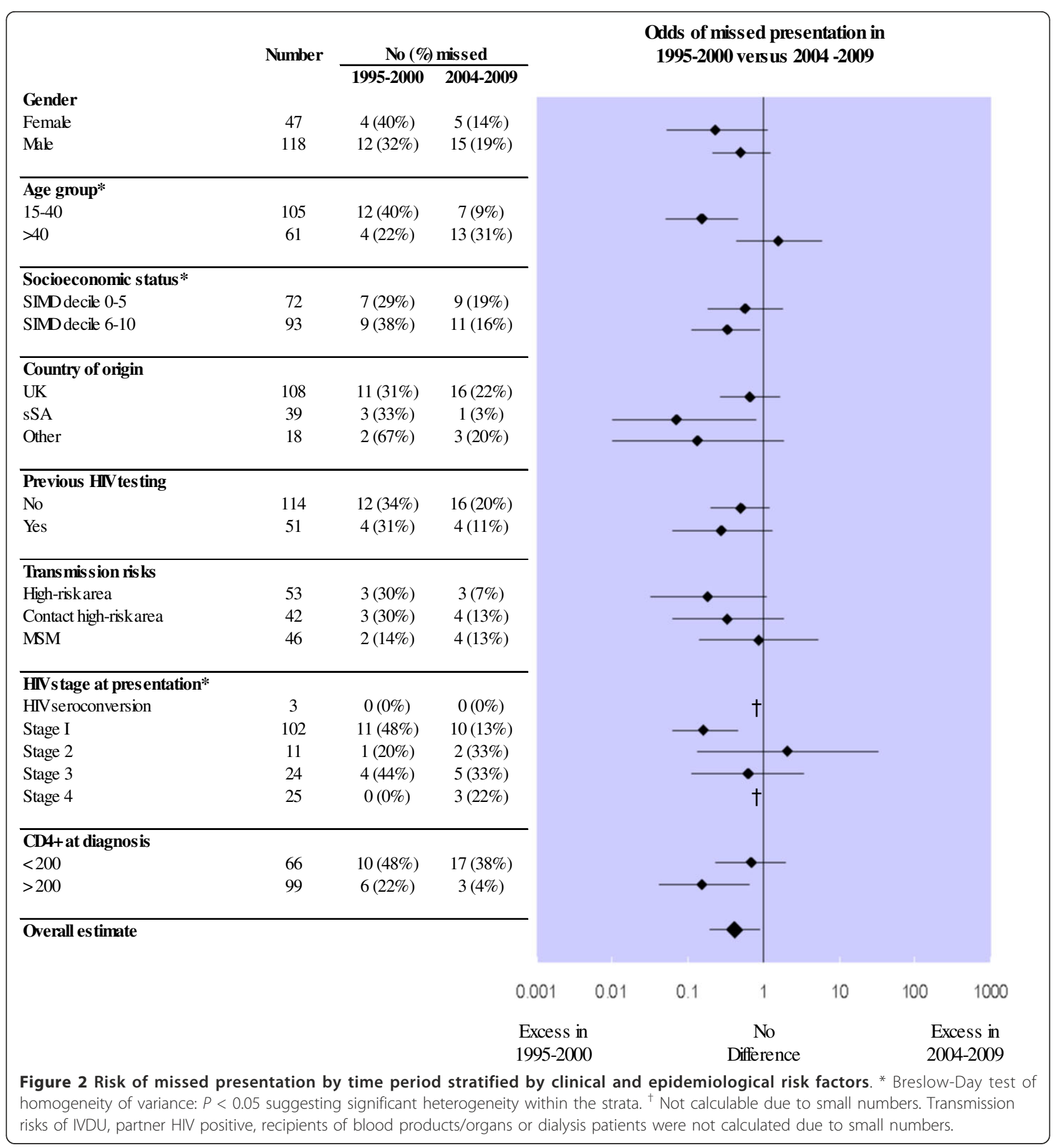

reflect the frequency of these presentations in nonspecialist services and immunocompetent patients. HIV related thrombocytopenia is common and not isolated to disease stage or risk group but is rarely profound or symptomatic [30]. Hepatitis C acquisition may be highest around the time of primary HIV infection [31]. Automatic flags for HIV testing on laboratory reports may help clinicians identify these presentations. Non-specificity of early HIV presentations remains a clinical challenge: while all AIDS defining illnesses prompted immediate diagnosis, we identified several commonly missed clinical indicators including, recurrent herpes zoster [32] oral candidiasis [33] and weight loss. By contrast recognition of primary HIV infection was better than reported elsewhere in the UK [34]. 


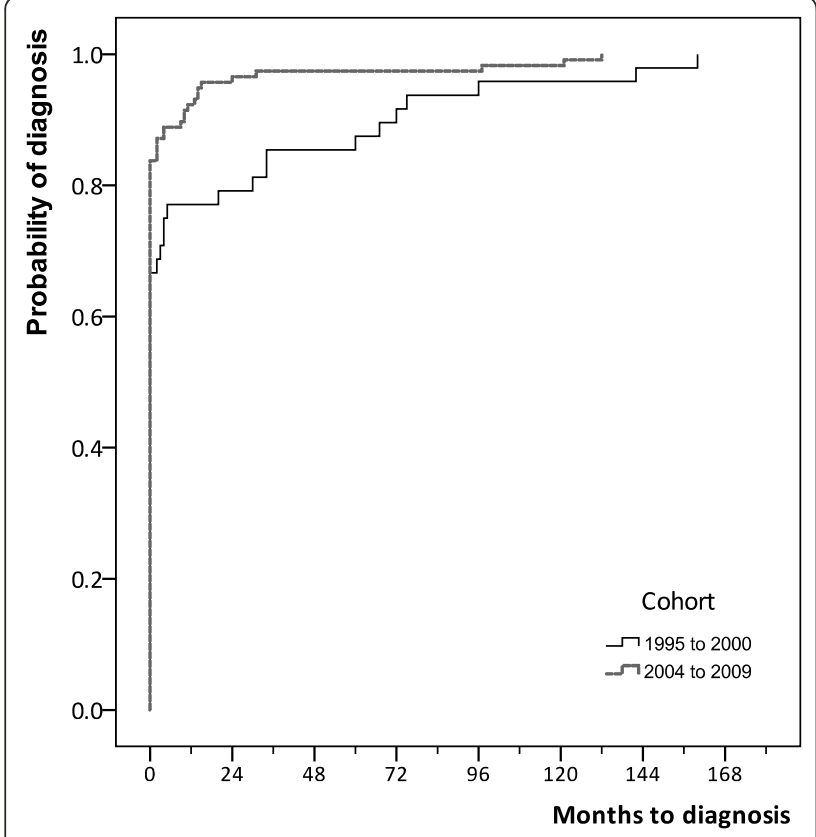

Figure 3 Kaplan-Meier curves of time to diagnosis from first presentation by cohort. (Log-rank test, $P=0.005$ ).

In common with previous studies [13,35] missed presentations were noted in both specialist and non-specialist services. Universal screening in services specified by national guidelines would have captured only $62 \%$ of new diagnoses and frequency of multiple missed presentations suggest need for improved HIV awareness at all care levels. The $27 \%$ of missed presentations identified in primary care supports emphasis on improving diagnosis in this setting [22]. A marked increase in contact with GUM services explains a significant improvement in diagnosis following an STI. The GUM model of care with anonymised records, drop-in facility and routine HIV testing may offer significant advantages in early HIV diagnosis, particularly if planned integration with primary care is realised [36].

The association of missed presentation and delay to diagnosis with immunological and clinical disease progression is well documented [37]. It is encouraging to note that the median time delay from missed presentation to diagnosis had fallen by 24 months between the first and second cohort. The disparity between reductions in missed presentation and non-significant decline in late or very late diagnosis may reflect shifts in demographics of all patients. In particular under-diagnosis and lack of documented health contact outside the UK create challenges to detection of HIV in migrants. Debate around the cost-effectiveness and practicability of universal 'opt-out' testing continues in the UK [38]. However our findings suggest that opportunistic testing presents considerable challenges to clinicians and public health. When opportunities to prevent transmission are added to those of improved survival after early diagnosis, the argument for routine HIV surveillance is persuasive $[11,38]$.

The generalisability of findings from this study may be limited by regional differences in HIV populations, testing and care provision arrangements. However, we believe the study highlights important challenges in opportunistic testing relevant to UK and similar healthcare settings. Limits to the internal validity of our findings arise from a retrospective design reliant upon records in secondary care. It was not possible to identify or include patients lost to follow up, or relocating out of area. A previous study of new HIV diagnoses between 1985 and 1997 suggest over representation of those of non-UK origin, students and prisoners in those discontinuing care within region [20]. Incomplete documentation in case-notes may mean failure to capture all relevant presentations or risk factors. However, systematic bias was minimised by a standardised data collection method for all patients with independent assessments of relevance of presentations by two investigators. Presentations in primary care were identified from printed summaries or documentations in case-notes from secondary care only, and may be under-represented. Investigation of missed presentations in this setting is an important priority [22]. Without concurrent control it is not possible to attribute trends in missed presentation to national strategies to improve HIV diagnosis [39]. Indeed our study suggests most improvements relate to changes in patient demographics and service provision. Further prospective, cluster randomised controlled trials of interventions to improve HIV diagnosis in general healthcare settings are required.

\section{Conclusions}

Early diagnosis of HIV infection is a priority in HIVrelated healthcare, but is complicated by changing socio-demographics of HIV populations in the UK. A significant reduction in missed presentations in North East Scotland was attributable to increased recognition of epidemiological risk-factors and contact with GUM services, rather than improvements in opportunistic testing of patients with clinical indicators. Consequently, missed opportunities for early diagnosis persist in populations considered at lower risk and presenting to non-specialist services. Diagnosis in those with haematological abnormalities or other blood-borne viruses might be improved by including advice on HIV testing in laboratory reports. However, evidence of disease progression after missed presentation further suggests the need to reconsider routine 'opt-out' testing in all general healthcare settings to reduce delays to HIV diagnosis. 


\section{Acknowledgements}

The authors would like to thank Dr. Graham Douglas, Dr. Ivan Tonna, Dr. Steve Baguley and Dr. Nair Vinuchandran for their editorial input on the final draft. In addition, we thank Dr. Steve Baguley and Dr. Nair Vinuchandran for providing data from the genito-urinary medicine department.

\section{Author details}

${ }^{1}$ School of Medicine and Dentistry, University of Aberdeen, Aberdeen, UK. 2Infection Unit, Aberdeen Royal Infirmary, Aberdeen, UK.

\section{Authors' contributions}

JW and RBSL conceptualised the study. JW, RBSL and TL were involved in the study design. JW and TL collected data. TL performed the statistical analysis. TL, RBSL and JW drafted the manuscript. All authors read and approved the final manuscript.

\section{Competing interests}

The authors declare that they have no competing interests.

Received: 17 August 2011 Accepted: 28 March 2012

Published: 28 March 2012

\section{References}

1. UNAIDS/WHO: Guidance on Provider-Initiated HIV testing and counselling in health facilities Geneva: World Health Organisation and Joint United Nations Programme on HIV/AIDS; 2006.

2. Centers for Disease Control and Prevention: HIV prevalence estimatesUnited States, 2006. Morb Mortal Wkly Rep 2008, 57(39):1073-1076.

3. European Center for the Epidemiological Monitoring of AIDS: End-Year Report 2006. EuroHIV 2007 [http://www.eurohiv.org/reports/report_75/pdf/ report_eurohiv_75.pdf].

4. De Cock KM, Johnson AM: From exceptionalism to normalisation: a reappraisal of attitudes and practice around HIV testing. BMJ 1998, 316(7127):290-293

5. Marks G, Crepaz N, Janssen RS: Estimating sexual transmission of HIV from persons aware and unaware that they are infected with the virus in the USA. AIDS 2006, 20:1447-1450.

6. Sabin CA, Smith CJ, Gumley H, Murphy G, Lampe FC, Phillips AN, Prinz B, Youle $M$, Johnson MA: Late presenters in the era of highly active antiretroviral therapy: uptake of and responses to antiretroviral therapy. AIDS 2004, 18(16):2145-2151.

7. Lucas SB, Curtis H, Johnson MA: National review of deaths among HIVinfected adults. Clin Med 2008, 8(3):250-252.

8. Fleishman JA, Yehia BR, Moore RD, Gebo KA: The economic burden of late entry into medical care for patients with HIV infection. Med Care 2010, 48(12):1071-1079.

9. Sir Liam Donaldson, CMO \& Christine Beasley, CNO: Improving the detection and diagnosis of HIV in non- HIV specialties including primary care.[http://www.info.doh.gov.uk/doh/embroadcast.nsf/vwDiscussionAll// EEOFA479BAA64A1B80257355003DFB47].

10. British HIV Association, British Association of Sexual Health and HIV, British Infection Society: UK National Guidelines for HIV Testing 2008 London: BHIVA/BASHH/BIS; 2008.

11. Sanders GD, Bayoumi AM, Sundaram V, Bilir SP, Neukermans CP, Rydzak CE, Douglass LR, Lazzeroni LC, Holodniy M, Owens DK: Cost-effectiveness of screening for HIV in the era of highly active antiretroviral therapy. New Engl J Med 2005, 352:570-585.

12. Sullivan AK, Curtis H, Sabin CA, Johnson MA: Newly diagnosed HIV infections: review in UK and Ireland. BMJ 2005, 330(7503):1301-1302

13. Ratcliffe L, Thomas S, Beeching NJ, Phillips-Howard PA, Taegtmeyer M: Acute presentations of HIV are still missed in low prevalence areas. Postgrad Med J 2011, 87(1025):170-174.

14. McDaid LM, Hart GJ: Increased HIV testing and reduced undiagnosed infection among gay men in Scotland, 2005-8: support for the opt-out testing policy? Sex Transm Infect 2011, 87(3):221-224.

15. World Health Organisation: Interim WHO clinical staging of HIV/AIDS and HIV/AIDS case definitions for surveillance. Geneva 2005.

16. Scottish Neighbourhood Statistics. [http://www.sns.gov.uk/, The Scottish Government.
17. Spencer N, Bambang S, Logan S, Gill L: Socioeconomic status and birth weight: comparison of an area based measure with the registrar general's social class. J Epidemiol Community Health 1999, 53:495-498.

18. Smith GD, Hart C, Watt G, Hole D, Hawthorne V: Individual social class, area-based deprivation, cardiovascular disease risk factors, and mortality: the Renfrew and Paisley Study. J Epidemiol Community Health 1998, 52:399-405.

19. World Medical Association Declaration of Helsinki: Ethical principles for medical research involving human subjects., Adopted 1964, Amended 1975, 1983, 1989, 1996, 2000, 2002, 2004 and 2008: [http:/www.wma.net/ en/30publications/10policies/b3/17c.pdf].

20. Mackenzie AR, Laing RB, Urbaniak SJ, Molyneaux PJ, Douglas JG, Smith CC: Epidemiology and outcome of HIV infection in North-East Scotland (1985-1997). J Infect 1999, 38(2):107-110.

21. Mabey $D$, Mayaud $P$ : Sexually transmitted diseases in mobile populations. Genitourin Med 1997, 73:18-22.

22. Burns FM, Johnson AM, Nazroo J, Ainsworth J, Anderson J, Fakoya A, Fakoya I, Hughes A, Jungmann E, Sadiq ST, Sullivan AK, Fenton KA, SONHIA Collaboration Group: Missed opportunities for earlier HIV diagnosis within primary and secondary healthcare settings in the UK. AIDS 2008, 22(1):115-122.

23. Delpierre C, Dray-Spira R, Cuzin L, Marchou B, Massip P, Lang T, Lert F, VESPA Study Group: Correlates of late HIV diagnosis: implications for testing policy. Int J STD AIDS 2007, 18(5):312-317.

24. Health Protection Agency Centre for Infections, Health Protection Scotland, UCL Institute of Child Health: United Kingdom New HIV Diagnoses to end of December 2010. London; Health Protection Agency; 2011.

25. Kaufmann GR, Bloch M, Finlayson R, Zaunders J, Smith D, Cooper DA: The extent of HIV-1-related immunodeficiency and age predict the longterm CD4 T lymphocyte response to potent antiretroviral therapy. AIDS 2002, 16(3):359-367.

26. Zenilman JM, Shahmanesh M, Winter AJ: Ethnicity and STIs: more than black and white. Sex Transm Infect 2001, 77(1):2-3.

27. Srinivasan R, Menon L, Stevens P, Campbell I, Alfaham M: Ethnic differences in selective neonatal BCG immunisation: white British children miss out. Thorax 2006, 61(3):247-249.

28. Gossop M, Powis B, Griffiths P, Strang J: Multiple risks for HIV and hepatitis B infection among heroin users. Drug Alcohol Rev 1994, 13:293-300.

29. Rodrigo T, Cayla JA, de Garcia Olalla P, Galdos-Tanguis H, Jansa JM, Miranda P, Brugal T: Characteristics of tuberculosis patients who generate secondary cases. Int J Tuberc Lung Dis 1997, 1(4):352-357.

30. Scaradavou A: HIV-related thrombocytopenia. Blood Rev 2002, 16(1):73-76.

31. Fox J, Nastouli E, Thomson E, Muir D, McClure M, Weber J, Fidler S: Increasing incidence of acute hepatitis $\mathrm{C}$ in individuals diagnosed with primary HIV in the United Kingdom. AIDS 2008, 22(5):666-668.

32. Hung CC, Hsiao CF, Wang JL, Chen MY, Hsieh SM, Sheng WH, Chang SC: Herpes zoster in HIV-1-infected patients in the era of highly active antiretroviral therapy: a prospective observational study. Int J STD AIDS 2005, 16(10):673-676

33. Johnson NW: The mouth in HIV/AIDS: markers of disease status and management challenges for the dental profession. Aust Dent J 2010, 55(Suppl 1):85-102.

34. Sudarshi D, Pao D, Murphy G, Parry J, Dean G, Fisher M: Missed opportunities for diagnosing primary HIV infection. Sex Transm Infect 2008, 84(1):14-16.

35. Lee V, Foley E, Patel R: Evaluation of time for non-GU medicine physicians to diagnose HIV infection in patients presenting with HIVrelated illnesses. Int J ST AIDS 2006, 17:97-98.

36. Aicken CR, Cassell JA, Estcourt CS, Keane F, Brook G, Rait G, White PJ, Mercer $\mathrm{CH}$ : Rationale and development of a survey tool for describing and auditing the composition of, and flows between, specialist and community clinical services for sexually transmitted infections. BMC Health Serv Res 2011, 11:30.

37. Castilla J, Sobrino P, De La Fuente L, Noguer I, Guerra L, Parras F: Late diagnosis of HIV infection in the era of highly active antiretroviral therapy: consequences for AIDS incidence. AIDS 2002, 16(14):1945-1951.

38. Hamill M, Burgoine K, Farrell F, Hemelaar J, Patel G, Welchew DE, Jaffe HW: Time to move towards opt out testing for HIV in the UK. BMJ 2007, 334(7608):1352-1354. 
39. Peck L, Ferenczi E, Burns F, Cosgrove C, Brown M: Barriers to targeted HIV testing on an acute admissions unit: evaluation of the UK guideline. QJM 2010, 103(3):147-151.

\section{Pre-publication history}

The pre-publication history for this paper can be accessed here: http://www.biomedcentral.com/1471-2334/12/72/prepub

doi:10.1186/1471-2334-12-72

Cite this article as: Wohlgemut et al:: Trends in missed presentations and late HIV diagnosis in a UK teaching hospital: a retrospective comparative cohort study. BMC Infectious Diseases 2012 12:72.

Submit your next manuscript to BioMed Central and take full advantage of:

- Convenient online submission

- Thorough peer review

- No space constraints or color figure charges

- Immediate publication on acceptance

- Inclusion in PubMed, CAS, Scopus and Google Scholar

- Research which is freely available for redistribution 